anales de psicología / annals of psychology

2019, vol. $35, \mathrm{n}^{\circ} 3$ (october), 405-416

http://dx.doi.org/10.6018/analesps.35.3.340091
(C) Copyright 2019: Editum. Servicio de Publicaciones de la Universidad de Murcia. Murcia (Spain) ISSN print edition: 0212-9728. ISSN on line edition (http://revistas.um.es/analesps): 1695-2294.

On line edition License Creative Commons 4.0: BY-NC-ND

\title{
Numeracy Musical Training for school children with low achievement in mathematics
}

\author{
Indira Arias Rodriguez ${ }^{1}$, Jessica M. Nascimento ${ }^{2}$, Marcos F. Voigt ${ }^{3}$, and Flávia H. Santos ${ }^{4}$ \\ 1 PhD student at the São Paulo State University, UNESP Bauru campus (Brazil) \\ 2 Master student at the São Paulo State University, UNESP Bauru campus (Brazil) \\ 3 Musician, Music Educator (Brazil) \\ 4 Professor at University College Dublin, UCD School of Psychology (Ireland)
}

\begin{abstract}
Título: Entrenamiento musical numérico para niños escolares con bajo rendimiento en matemáticas.

Resumen: El presente estudio caso-control, doble ciego, y prospectivo investigó los efectos del entrenamiento musical numérico (NMT; Numerac) Musical Training), sobre habilidades cognitivas en niños de enseñanza primaria. Participaron 42 niños de 8 a 10 años divididos en dos grupos: con Bajo Rendimiento Aritmético $(N=21)$, y con Rendimiento Aritmético Medio $(N=21)$. Los niños pasaron por dos evaluaciones, antes y después de la realización del NMT, en las cuales se aplicaron pruebas cognitivas y escalas de comportamiento, que evaluaban variables como: rendimiento escolar, CI, memoria operativa, cognición numérica, ansiedad y estrés. El NMT fue desarrollado en ocho sesiones colectivas y tuvo como objetivo estimular los sistemas de la cognición numérica e integrar conocimientos musicales básicos y representaciones simbólicas. Después de la intervención por medio del entrenamiento musical los niños de ambos grupos obtuvieron mejoras significativas en el rendimiento académico, en los sistemas de la cognición numérica y en la memoria operativa, así como una disminución de la manifestación de ansiedad a las matemáticas.

Palabras clave: Entrenamiento musical; cognición numérica; memoria operativa, Discalculia del Desarrollo.
\end{abstract}

\section{Introduction}

Low arithmetic achievement or LA (Mazzocco, 2007) tends to be transitory and mainly determined by environmental factors (Mazzocco \& Räsänen, 2013; Räsänen, Salminen, Wilson, Aunio, \& Dehaene, 2009). It is a common condition in the school environment and may be worsened, if there is 'continuous progression in primary school', a measure applied in the Brazilian education system where children can progress in certain grades without having achieved the planned aims (Menezes \& Santos, 2001).

Importantly, LA can mask the presence of mathematical learning disability, which on the contrary is inherent. For instance, Silva and Santos (2011) and Arias-Rodríguez, Nascimento, and Santos (2017) researched several aspects of numerical cognition and working memory in children with an LA profile, who showed deficits in number processing, calculation and visuospatial working memory. However, deficits of some children in the sample (57.14\%) were compatible with Developmental Dyscalculia (DD), since elementary performance of addition, subtraction, multiplication and division was at least 1.5 standard deviation below that expected for age and corresponded to a delay of

* Correspondence address [Dirección para correspondencia]: Dr. Flávia Santos. University College Dublin, UCD School of Psychology, F202 Newman Building, Belfield Dublin 4 (Ireland).

Email: flavia.santos@ucd.ie

(Article received: 4-9-2018; revised: 27-9-2018; accepted: 24-4-2019)
Abstract: The present case-control, double-blind, and prospective study investigated the effects of Numeracy Music Training (NMT) on cognitive skills of primary school children. Participating in the study were 42 children aged 8 to 10 years divided into two groups: Low Achievement in Math $(N=21)$, and Average Achievement in Math $(N=21)$. The children underwent two assessments before and after NMT. Cognitive tests and behaviour scales were applied regarding variables such as school performance, IQ, working memory, numerical cognition, math's anxiety and stress. NMT was developed in eight group sessions and aimed to stimulate the systems of numerical cognition and integrate basic musical knowledge, and symbolic representations. After the intervention, through musical training, the children in both groups showed significant improvements in school performance, systems of numerical cognition and working memory, as well as the reduction of mathematics anxiety symptoms.

Keywords: musical training; numerical cognition; working memory, Dyscalculia Development

two years of school grade taken; and this difficulty was not linked to inadequate teaching or intellectual disability neither to sensorial deficits (ICD-11, WHO, 2018; DSM-V, APA, 2013). In fact, the persistence and severity of equivalent deficits are criteria for the diagnosis of DD (Kaufmann et al., 2013).

The International Consensus indicated that when deficits in math are attributed exclusively to numerical cognition dysfunctions in the absence of comorbidities with other disorders and of impairments in other cognitive abilities, they should be classified as primary DD (Kaufmann \& von Aster, 2012; Kaufmann et al. al., 2013). However, children with deficits in numerical cognition linked with non-numerical cognitive dysfunctions, e.g. in working memory (Pina, Fuentes, Castillo \& Diamantopoulou, 2014) and those with comorbid neurodevelopmental disorders should be classified as secondary DD (Kaufmann et al. al., 2013).

Devine, Soltész, Nobes, Goswami, and Szűcs (2013), based on 17 epidemiological studies indicated that prevalence of DD is around 5-6\%, their survey carried out with 1004 British children showed an equal presence of the disorder in boys and girls, depending on the inclusion criteria (Devine, et al., 2013). The study by Bastos, Cecato, and Martins (2016) analysed the prevalence of DD in Brazilian primary school children $(n=226)$ and concluded that $7.8 \%$ met disorder criteria. Results analysis showed a higher prevalence among male children from schools in more vulnerable neighbourhoods, from parents with little schooling. Such sample characteristics suggest the presence of children with 
an LA profile among those with DD (Kaufmann et al., 2013; Mazzocco \& Räsänen, 2013).

Children with DD are vulnerable to risks such as persistent learning difficulties, school abandonment and emotional instability (Snyder \& Bambara, 1997), which can permanently impair their emotional functioning, schooling and future professional career (Herrera \& Maldonado, 2002). These children may acquire a negative attitude towards the subject, often characterized by a specific anxiety to mathematics (Krinzinger, Kaufmann, \& Wilmes, 2009; Ramírez, Chang, Maloney, Levine, \& Beilock, 2016; Rubinsten \& Tannock, 2010). Therefore, in these cases remediation is a sustained challenge.

Computerized training for numerical cognition in children with DD currently seems effective both for number sense (Wilson, Revkin, Cohen, \& Dehaene, 2006) and for the mental number line (Kucian et al., 2011). Studies indicate remediation alternatives in the field of neuroscience (GraciaBafalluy \& Escolano-Pérez, 2014); Numerical cognition tutorial (Iuculano et al., 2015), although these interventions are generally individual. However, music can stimulate mathematics learning without using routine school activities, thus being more ecological and inclusive (Katsh \& MerleFishman, 1985). According to Eugênio, Escalda and Lemos (2012), musical learning always provides mathematical challenges, since the basis of musical theory and sound acoustics follow mathematical calculations.

The experience of musicalisation, for example, showed beneficial effects toward working memory. Ribeiro and Santos (2012) assessed children of 9 and 10 years of age, beginners and advanced in a musicalisation programme for one hour per week, compared to a control group that did not perform any regular and monitored musical activity. The evaluation of the working memory showed that children more exposed to the music programme presented better scores than beginners and no-exposed participants in both short-term memory tasks and working memory. This effect was seen in verbal and visuospatial modality tasks. This is due to the fact that music, language, reading and mathematics share some acoustic properties such as pitch, rhythm and timbre, so, stimulated by music, children can learn these concepts faster (Anvari, Trainor, Woodside, \& Levy, 2002; Ribeiro \& Santos, 2015).

Koelsch and Siebel (2005) pointed out that musical training produces a cognitive effect because it activates complex brain functions such as: acoustic analysis, auditory memory, transformation of interval relationships, syntax and musical semantics, as well as activation and representation of actions. In addition, contact with music elicits emotions, which stimulate the subjective sensations, autonomic nervous, hormonal and immune systems, bringing a feeling of well-being (Koelsch \& Siebel, 2005).

Prospective studies observed different cognitive effects depending on the musical training characteristics. For 'instrumental musical training', one requiring regular keyboard or piano practice, benefits were found in the processing of verbal and visual working memory (Ho, Cheung, \& Chan, 2003), reasoning (Moreno et al., 2011; Schellenberg \& Mankarious, 2012) and visuospatial skills (Costa-Giomi, 1999; Rauscher \& Zupan, 2000). In 'non-instrumental musical training', where musical experiences with voice and perception of sounds predominate, benefits derived from the musical experience were observed in skills such as abstract reasoning, numerical cognition and working memory (Anvari et al., 2002; Rauscher et al., 1997; Ribeiro \& Santos, 2012; Ribeiro \& Santos, 2015; 2017; Silva, Baldin, \& Santos, 2017). Students taking part in non-instrumental musical training linked to the learning of abstract representation and geometry, outperformed peers with little or no musical experience in tasks involving numerical and visuospatial mastery and improved performance in mathematics.

Other evidence suggests that music training can be a tool in the remediation of learning disorders in mathematics (Ribeiro \& Santos, 2017) or its prevention (Silva, Baldin, \& Santos, 2017). Esteki (2013) evaluated the effect of musical stimulation for the neurocognitive structuring of 13 girls, between 7 and 9 years old, diagnosed with DD. Following the 16 musical sessions, there were changes in the activities of different regions of the brain, particularly the parietal and frontal lobes, together with improvements in tasks regarding the intelligence coefficient (verbal and non-verbal), attention and numerical memory, in contrast with pre-training assessment. However, the authors do not detail the training methodology, or the cognitive activities assessed, which limits comparisons with future studies.

Adopting a structured and replicable methodology, Ribeiro and Santos (2017) evaluated the effect of noninstrumental musical training on the numerical cognition of children with DD. The study involved 46 children of 8 years old, with seven rhythmic sessions and seven auditory sessions, divided into four mixed groups. The pre-training cluster analysis divided participants into groups, one clinical and one control, coinciding with the numerical cognition battery scores specialized in the diagnosis of DD. However, in the post-training cluster analysis, some children in the clinical group, who increased their performance in numerical cognition, became identified among the controls.

Silva, Baldin, and Santos (2017) researched the effects of the numeracy musical training (NMT), a specific noninstrumental music training programme designed to stimulate numerical cognition. It was a prospective, randomized and controlled study in a sample of 57 preschoolers with typical development, aged 5 years. The Experimental group $(n=$ 25) participated in eight NMT sessions while the control group $(n=32)$ did not take part in training but remained in school in regular pedagogical activities. All participants were assessed in abstract reasoning, verbal and visuospatial working memory and numerical cognition in two moments. The results of the post-training assessment of the experimental group suggested progress in learning skills, specifically in mathematics and working memory compared to pre-training, which were not observed in the control group. 
The present research is the first study using the NMT for a sample of school children with low achievement in mathematics. In order to test this methodology in a more ecological way, NMT was performed in mixed but balanced groups, i.e., children with and without difficulties in mathematics. This approach has already been adopted in other casecontrol studies (Kucian et al., 2011; Michels, O'Gorman, \& Kucian, 2017) where controls also took part in the training. The collective training promotes inclusive behaviour and socialization during the intervention (Silva, Baldin, \& Santos, 2017).

In this way, the aim of this study was to investigate NMT effects on school performance, numerical cognition (number sense, number production and comprehension, calculation), working memory and behavioural aspects in school-age children with low or medium academic performance through neurocognitive assessments at two moments, Pre and Post NMT. Study hypothesis is that NMT will produce near transfer effects in arithmetic systems (explicitly stimulated) and less expressive far transfer effects in other non-stimulated cognitive abilities, such as visuospatial reasoning.

\section{Method}

\section{Experimental Design}

This was a double-blind prospective case-control study. All children took part in the NMT; the sample was divided into two balanced groups: case (children with low arithmetic achievement) and control (children with average arithmetic achievement). The study was blind, the music teacher was not informed of the performance of the children in the preNMT evaluation and which children belonged to each condition. In addition, the psychologists performing the neuropsychological evaluations were not informed of the performance of the children during music training. The children were assessed in two moments (pre- and post-NMT) with the same instruments. Besides, parents did not receive information about the participation of their children in the study before training finished. For intervention, the children were allocated to the four groups in a pseudo-random manner, as described in procedures.

\section{Estimation of sample size}

The a priori sample size was calculated based on evaluation of intra-group and inter-group interactions with repeated measures. For an effect size of $.40, .05$ and power $(1-\beta)=$ .95 , a sample of 24 subjects was needed. In the current study we analysed data from 42 children, which therefore had enough statistical power.

\section{Participants}

Initially, 310 children were recruited for the study, all from two public schools in Bauru, São Paulo State, Brazil.
The participating centres reached the national average in the Development Index of Basic Education (Ideb) of 2011, with a higher grade than 5.0 in the initial grades (first to fifth) corresponding to the OECD international level, based on evaluation of the Education Development Index of the State of São Paulo (IDESP) of 2013. The city has an HDI - Human Development Index of 0.80 classified as high (UNDP, 2010).

The case group, labelled as LA, met the following inclusion criteria: (a) mathematics difficulties reported by the child's teacher, b) cut-off grade in arithmetic test (Stein, 1994) <9 (third grade children) or $<14$ fourth grade children), provided in the School Performance Test handbook, as a result lower than expected for the grade taken, however, with expected abstract reasoning for their chronological age. Twenty-one children fulfilled the criteria, corresponding to $6.7 \%$ of the sample. Then a control group was matched to them.

For the control group, labelled as AA, besides general criteria, inclusion criteria were not repeating a school grade, no learning disorders, nor complaints of learning difficulties. For both groups, exclusion criteria were the presence of previously diagnosed psychiatric or neurological comorbidities and the use of psychoactive substances.

Participants were 42 children, 18 boys and 24 girls, aged between 8 and 10 years, were selected for the study. Based on screening results, i.e. the measure of school performance in arithmetic, b) children were assigned in two groups: low arithmetic achievement $(\mathrm{LA}=21)$ and average arithmetic achievement $(\mathrm{AA}=21)$. Portuguese was the mother tongue of all children and they did not receive independent music classes for music training, nor did the schools have a music teacher. Data is presented in Table 1.

Table 1. Sociodemographic aspects of the sample.

\begin{tabular}{llll}
\hline Age in years & 8 & 9 & Total \\
\hline $\mathrm{N}(\%)$ & $16(45.24)$ & $26(61.90)$ & $42(100)$ \\
Sex $(\%)$ boys & $7(16.67)$ & $11(26.19)$ & $18(42.86)$ \\
Sex $(\%)$ girls & $9(21.40)$ & $15(35.71)$ & $24(57.14)$ \\
\hline N $(\%)$ distribution of school years according to age & \\
\hline $3^{\circ}$ & $10(23.81)$ & - & $10(23.81)$ \\
$4^{\circ}$ & $6(14.29)$ & $26(61.90)$ & $32(76.19)$ \\
\hline
\end{tabular}

\section{Procedure}

The study was approved by the Ethics Committee of the UNESP, consent terms were signed, and children provided assent.

Neuropsychological evaluation was performed in three individual sessions lasting a maximum of 50 minutes. A semi-random order (interspersing verbal and non-verbal subtests) was used to avoid fatigue, pencil and paper tasks were conducted before computerized tasks. The instruments were always applied in the same order of exposure (intelligence, numerical cognition and working memory) for all children in the two evaluations. The period of Pre-NMT and Post-NMT evaluations took two months each to be completed. 
To assign children to the intervention groups, pseudorandomized criteria such as sex and year of study were respected, structured according to the availability of schedules for each school class. Thus, 4 NMT classes were formed (two with $N=11$ and two with $N=10$ ), organized in a mixed and balanced way. NMT was performed by Marcos Voigt, musician and musical teacher, who, made musical arrangements based on original music according to the aims of the sessions. Activities were developed on the school premises in the same class period, in a room which was noise-free and had ample physical space and multimedia.

\section{Materials}

Anamnesis: adapted from the questionnaire prepared by Santos (2002). Raven's Coloured Progressive Matrices RCPM (Raven, 1992), Brazilian adaptation (Angelini, Alves, Custódio, Duarte, \& Duarte, 1999). School Achievement Test (Stein, 1994). Neuropsychological Tests Battery for Number Processing and Mental Calculation in children, revised version, Zareki-R (von Aster \& Dellatolas, 2006), Brazilian adaptation and normative data presented by Santos, et al. (2012). Automated Working Memory Assessment ([AWMA], Alloway, 2007); Brazilian adaptation (Santos \& Engel, 2008). Inventory of Stress Symptoms in Children ([ISS-I], Lipp \& Lucarelli, 1998). Math Anxiety Scale ([EAM], Carmo and Figueiredo (2005), Self-efficacy questionnaire for children (SEQ-C) (Nogueira, 2003). For test description, see Ribeiro and Santos (2012) and Arias-Rodríguez, Nascimento, and Santos (2017).

\section{Numeracy Musical Training (NMT)}

Musical training requires multi-modality and multisensorial resources within embodied, embedded, extended, enactive activities (Schiavio \& van der Schyff, 2018). The NMT was developed as an attractive music programme with specific activities to stimulate the four systems of numerical cognition (von Aster \& Shalev, 2007). The activities in each session aimed to increase specific mathematical competencies and integrate basic musical knowledge and symbolic representations. All activities were presented hierarchically, beginning with minor tasks for greater complexity, by errorless strategy seeking automation without errors during the performance (Melo, Hanna, \& Carmo, 2014).

The original program was prepared in Spanish and focused on preschool children. For the present research we used the Portuguese translation of Silva, Baldin, and Santos (2017) with a minor adaptation regarding complexity, i.e. multiplication and division exercises were added to the original program in order to be suitable for children of school age. However, the visual stimuli of Antonio Sánchez Capel (art designer) and the recorded sounds developed by the pianist Carlos Campoy were the same as originally for NMT.

The developed program comprised eight weekly sessions lasting 40 minutes each and was carried out over two months. Each NMT session included 5 minutes of warm-up and 5 minutes of relaxation at the end of each session, training was divided into three types of techniques of 10 minutes each: 1) rhythmic stimulation (pulse and stress), 2) melodic stimulation (timbre and song), and 3) tone stimulation (bass / treble). The children's voices and bodies were the source of sounds in the first four sessions, and musical instrument sounds were implemented in the last four sessions.

Audiovisual resources were used as support material for all sessions and to reinforce information given by the music teacher. As for songs, the pieces were played with a guitar accompaniment using gestures and movements to stimulate the perception of "quantities" and mathematical symbols contained in the songs, since these are the gestures that promote the activation of the neural circuits involved in learning mathematics (Cohen-Kadosh \& Walsh, 2009). The complete content of each session and NMT task has been detailed previously (Silva et al., 2016). NMT sessions in school-age children were structured as follows:

Session 1. Cardinal System. Rhythm. Training of specific amounts and the children's ability to count and add. Melo$\mathrm{dy}$, the children sang a song involving numbers. Pitch, classification of sounds of nature, mainly animal "voices" in bass and treble.

Session 2: Numerical verbal system. Rhythm, the children turned numbers into words, clapping to the number of syllables. Melody: the children sang a song about quantities. Tone: The musical notes were presented, for recognition and discernment in bass and treble.

Session 3: Visual numerical system. Rhythm: The children recognized the Arabic number system, and then the sum of these amounts was trained. Melody: They sang a song involving Arabic numerals. Tone: With recordings the children discriminated between the bass and treble sounds of two musical notes.

Session 4: Ordinal system. Rhythm: The children walked on a number line on the floor. Melody: They then sang a song using the floor number line. Tone: the children marked the relationship between the duration of a sound throughout the music.

Session 5: Cardinal system. Rhythm: Size estimation was trained, as well as mental calculation (addition and multiplication), producing the sound of a musical note and walking on the number line on the floor to the corresponding amount. Melody: the children sang a song using their fingers to represent quantities. Tone: auditory discrimination of musical notes: same or different.

Session 6: Verbal numerical system. Rhythm: coding was trained; children tapped their feet to the number of syllables of the words. Melody: children learned numbers visually, performing corresponding gestures and singing. Tone: discriminating the sounds of long sequences of notes in high and low frequency.

Session 7: Visual numerical system. Rhythm: Children performed operations (subtraction and division) with gesture and images support. Melody: they sang a song involving 
"subtraction". Tone: The children discriminated sounds of musical notes with short sequences of 2 and 3 notes.

Session 8: Ordinal system. Rhythm: Children performed subtraction and division operations using images. A choral chant was carried out. Melody: a song was freely chosen. Tone: Half of the children sang in a treble tone and the other half in bass.

\section{Statistical analysis}

Analyses were developed using the SPSS program version 21.0. Initially, data were subjected to descriptive analysis of variables, determining percentage, averages and standard deviations.

The prospective study was evaluated through the ANOVA statistical test of repeated measures, contrasting intersubject factors (LA x AA) and intra-subjects (pre- and postNMT). The Bonferroni post-hoc test was used for all comparisons. The Greenhouse-Geisser correction was applied to evaluate F-ratios (relationships). The adopted significance level was $\mathrm{p} \leq .05$ and for the evaluation of the group effect size the square eta $\left(\eta^{2}\right)$ was used for repeated measures ANOVA, $\left(\eta^{2}>.45\right.$, was considered a large effect). Relative gain was calculated by the formula average post-test minus average pre-test divided by the average pre-test.

\section{Results}

In clinical records, no significant differences were found between the LA and AA groups in birth and weight variables. As regards neuropsychomotor development, LA children took longer to acquire cervical control $(t=3.08, p=.04, d=$ $.98)$ and trunk $(t=2.04, p=.04, d=2.90)$. Learning to walk and language were similar in comparison. There were similarities between groups regarding the mother's personal history; presented for each group: 2 cases of hypertension, 1 threat of miscarriage and 1 haemorrhage, representing $19.05 \%$ of incidence for each group. As for socioeconomic status, families receive the equivalent of about two monthly minimum wages in Brazil (salary: $M=1680.00, S D=134.40$, or $=394$ $€)$.

In Abstract Reasoning analysis the Percentile showed time effects, reporting an improvement for both AA and LA groups in the second evaluation ( $p s=.01)$, neither Group effect nor interaction effect were found.

Regarding Numerical Cognition, the Zareki-R subtest was analysed to research the implications of exposure to numerical cognition training in children and scores [Mean (standard deviation)] are presented in Table 2 . The only tasks where no differences were found between pre and post-NMT evaluations nor between LA x AA groups nor interactions between groups and evaluations were the counting dots and perceptive estimation.

Table 2. Scores [Mean (Standard Deviation)] obtained by groups LA and AA for abstract reasoning, School Achievement Test and ZAREKI-R.

\begin{tabular}{|c|c|c|c|c|c|c|c|c|c|}
\hline \multirow[b]{2}{*}{ Abstract reasoning } & \multicolumn{2}{|c|}{ LA $(N=21)$} & \multicolumn{4}{|c|}{$\mathrm{AA}(N=21)$} & \multirow[b]{2}{*}{ Effects } & \multirow[b]{2}{*}{$F$} & \multirow[b]{2}{*}{$p \quad \eta^{2}$} \\
\hline & Pre-NMT & Post- NMT & RG & Pre- NMT & Post- NMT & RG & & & \\
\hline \multirow[t]{3}{*}{$\overline{\mathrm{RCPM}}$} & $24.62(4.03)$ & $27.10(2.96)$ & .10 & $26.52(4.73)$ & $31.48(2.96)$ & .18 & Group & 3.50 & .10 .10 \\
\hline & & & & & & & Time & 13.70 & $<.01 \quad .30$ \\
\hline & & & & & & & Interaction & 3.00 & $.10 \quad 10$ \\
\hline \multicolumn{10}{|c|}{ School Achievement } \\
\hline \multirow[t]{3}{*}{ Writing } & $17.95(5.85)$ & $23.47(5.34)$ & .31 & $26.33(3.65)$ & $28.42(4.98)$ & .08 & Group & 14.00 & .01 .26 \\
\hline & & & & & & & Time & 1494.3 & $<.01 .99$ \\
\hline & & & & & & & Interaction & 7.40 & .01 .16 \\
\hline \multirow[t]{3}{*}{ Arithmetic } & $9.80(2.80)$ & $13.42(2.50)$ & .36 & $15.61(3.58)$ & $17.42(2.58)$ & .10 & Group & 37.70 & $<.01 \quad .49$ \\
\hline & & & & & & & Time & 45.50 & $<.01 \quad .53$ \\
\hline & & & & & & & Interaction & 5.05 & $.03 \quad .11$ \\
\hline \multirow[t]{3}{*}{ Reading } & $62.19(5.35)$ & $65.42(3.32)$ & .05 & $67.33(3.23)$ & $68.42(2.83)$ & .02 & Group & 25.70 & $<.01 .39$ \\
\hline & & & & & & & Time & 154.40 & $<.01 \quad .79$ \\
\hline & & & & & & & Interaction & 5.20 & $.02 \quad .11$ \\
\hline \multirow[t]{3}{*}{ Total } & $89.90(11.12)$ & $102.10(9.14)$ & .14 & $108.9(8.45)$ & $114.2(8.54)$ & .05 & Group & 3.80 & $<.01 .44$ \\
\hline & & & & & & & Time & 15.80 & $<.01 \quad .80$ \\
\hline & & & & & & & Interaction & 23.00 & $<.01 .36$ \\
\hline \multicolumn{10}{|c|}{ Numerical Cognition } \\
\hline \multirow[t]{3}{*}{ Counting Dots } & $3.28(0.71)$ & $3.52(0.51)$ & .07 & $3.61(0.58)$ & $3.66(0.65)$ & .01 & Group & 3.90 & $.06 \quad .09$ \\
\hline & & & & & & & Time & 1.00 & $.33 \quad .02$ \\
\hline & & & & & & & Interaction & .40 & .50 .11 \\
\hline \multirow[t]{3}{*}{ Perceptive Estimation } & $5.33(2.30)$ & $6.66(2.63)$ & .25 & $7.23(2.23)$ & $7.33(2.03)$ & .01 & Group & 2.80 & .07 \\
\hline & & & & & & & Time & 4.00 & $.06 \quad .09$ \\
\hline & & & & & & & Interaction & 2.00 & .16 .47 \\
\hline \multirow[t]{3}{*}{ Counting Backward } & $2.14(1.31)$ & $3.19(1.12)$ & .49 & $3.66(0.48)$ & $3.95(0.21)$ & .08 & Group & 7.00 & $.01 \quad .20$ \\
\hline & & & & & & & Time & 1701.1 & $<.01 .98$ \\
\hline & & & & & & & Interaction & 6.91 & $.01 \quad .10$ \\
\hline
\end{tabular}




\begin{tabular}{|c|c|c|c|c|c|c|c|c|c|c|}
\hline \multirow[b]{2}{*}{ Abstract reasoning } & \multicolumn{2}{|c|}{ LA $(N=21)$} & \multicolumn{4}{|c|}{ AA $(N=21)$} & \multirow[b]{2}{*}{ Effects } & \multirow[b]{2}{*}{$F$} & \multirow[b]{2}{*}{$p$} & \multirow[b]{2}{*}{$\eta^{2}$} \\
\hline & Pre-NMT & Post- NMT & RG & Pre- NMT & Post- NMT & RG & & & & \\
\hline \multirow{3}{*}{ Dictation of Numbers } & $11.33(3.49)$ & $14.19(2.44)$ & .25 & $15.33(1.01)$ & $15.66(0.73)$ & .02 & Group & 16.20 & $<.01$ & .30 \\
\hline & & & & & & & Time & 1866.1 & $<.01$ & .98 \\
\hline & & & & & & & Interaction & 26.42 & $<.01$ & .40 \\
\hline \multirow[t]{3}{*}{ Reading Numbers } & $12.85(3.66)$ & $14.57(2.61)$ & .13 & $15.42(2.20)$ & $16.00(0.00)$ & .03 & Group & 8.30 & $<.01$ & .20 \\
\hline & & & & & & & Time & 26.60 & $<.01$ & .40 \\
\hline & & & & & & & Interaction & 11.23 & $<.01$ & .20 \\
\hline \multirow[t]{3}{*}{ Positioning Numbers } & $14.29(4.44)$ & $19.81(3.46)$ & .39 & $21.81(1.78)$ & $22.67(1.71)$ & 0.04 & Group & 23.58 & $<.01$ & .39 \\
\hline & & & & & & & Time & 44.01 & $<.01$ & .52 \\
\hline & & & & & & & Interaction & 2308.8 & $<.01$ & .98 \\
\hline \multirow[t]{3}{*}{ Oral Comparison } & $13.23(2.54)$ & $14.38(1.49)$ & .09 & $14.71(1.23)$ & $15.23(0.99)$ & .03 & Group & 4.40 & .04 & .10 \\
\hline & & & & & & & Time & 611.10 & $<.01$ & .94 \\
\hline & & & & & & & Interaction & 1.00 & .30 & .02 \\
\hline \multirow[t]{3}{*}{ Written Comparison } & $18.38(2.57)$ & $19.23(2.23)$ & .05 & $19.14(3.07)$ & $19.23(2.23)$ & .004 & Group & 1.30 & .30 & .03 \\
\hline & & & & & & & Time & .90 & .40 & .02 \\
\hline & & & & & & & Interaction & .60 & .40 & .01 \\
\hline \multirow[t]{3}{*}{ Contextual Estimation } & $9.80(3.73)$ & $13.14(4.45)$ & .34 & $11.23(4.02)$ & $15.42(3.04)$ & .37 & Group & 10 & .80 & .02 \\
\hline & & & & & & & Time & 34.90 & $<.01$ & .40 \\
\hline & & & & & & & Interaction & .60 & .40 & .02 \\
\hline \multirow[t]{3}{*}{ Mental Calculation } & $14.80(10.03)$ & $23.28(8.74)$ & .56 & $33.61(4.92)$ & $33.09(6.94)$ & -.01 & Group & 26.30 & $<.01$ & .40 \\
\hline & & & & & & & Time & 12.10 & $<.01$ & .23 \\
\hline & & & & & & & Interaction & 15.50 & $<.01$ & .27 \\
\hline \multirow[t]{3}{*}{ Problem Solving } & $4.09(3.19)$ & $8.90(3.70)$ & .10 & $10.57(1.66)$ & $11.23(1.33)$ & .06 & Group & 28.60 & $<.01$ & .42 \\
\hline & & & & & & & Time & 29.90 & $<.01$ & .43 \\
\hline & & & & & & & Interaction & 26.70 & $<.01$ & .40 \\
\hline \multirow[t]{3}{*}{ Memory of Digits } & $20.19(4.00)$ & $25.62(5.68)$ & .30 & $21.52(3.63)$ & $25.81(5.47)$ & .20 & Group & 12.00 & .01 & \\
\hline & & & & & & & Time & 29.70 & $<.01$ & \\
\hline & & & & & & & Interaction & 7.70 & .01 & .21 \\
\hline \multirow[t]{3}{*}{ Total } & $109.66(20.89)$ & $141.28(23.1)$ & .30 & $157.23(10.49)$ & $162.95(11.38)$ & .03 & Group & 42.90 & $<.01$ & \\
\hline & & & & & & & Time & 89.10 & $<.01$ & \\
\hline & & & & & & & Interaction & 3274.7 & $<.01$ & .98 \\
\hline
\end{tabular}

Note. NMT: numeracy musical training. LA: low arithmetic achievement, AA: average arithmetic achievement, RG: relative gain. Relative Gains. ZAREKIR. Neuropsychological Tests Battery for Number Processing and Mental Calculation in children, revised version, RCPM: Raven's Coloured Progressive Matrices.

In subtests, counting backward, dictation of numbers and reading numbers, the LA group had lower scores compared to the AA group and differences were significant. The preand post-NMT comparisons showed improvements given by the superior results in the second evaluation. The results of the interactions between groups and evaluations indicate that although both groups achieved better scores in these analysis areas in the second evaluations, differences remained between the groups, the AA children presented higher results than LA children ( $p s=.01)$.

There were differences between the LA and AA groups for the oral comparison subtest: for the other tasks, written comparison and contextual estimation, results were similar for LA and AA. On the other hand, there was a time effect in comparison between NMT pre - post evaluations for the three subtests. However, no significant interactions were found for either three subtests, the groups maintained similar results among themselves, obtaining better scores in posttraining evaluation ( $p s<.01$ ); written comparison showed better scores in the post-NMT evaluation where AA children presented higher results than their LA peers $(p s=.49)$. For contextual estimation, significant differences were found between the pre- and post-NMT evaluations. In the first, the
LA children showed lower results to their peers, which were compensated in the second evaluation where both groups of children obtained similar results. $(p s<.01)$

For the subtest related to Calculus, there was a group effect where the performance of children with AA was higher than children with LA. Analyses also reported expressive improvements in post-NMT evaluations: for mental calculation and problem solving, accompanied by group interactions and evaluations for both. Even when significant improvements in the post-NMT evaluation were perceived, the results of LA children were much lower than those of their AA peers, AA children remained with similar scores in both calculation evaluations $(p s<.01)$ and problem solving ( $p s<.001)$.

The result of the total Zareki-R score, which is a parameter for diagnosis of Developmental Dyscalculia, in pre-NMT evaluation it was seen that $100 \%$ of participants with LA had lower than expected results with scores equivalent to the delay of one school grade. In addition, 13 cases $(61.90 \%)$ of the 21 LA children $(N=5$ of third grade and $N=8$ of fourth grade), did not achieve expected results for two previous school grades. There were more severe deficits for 3 of the 16 children in the fourth grade whose results did not reach 
those expected for children with typical development from the first grade of primary education.

In post-NMT evaluation, 6 of the $21(28.47 \%)$ LA children achieved expected results for their age, 15 of the $21 \mathrm{LA}$ children $(71.43 \%)$ continued without reaching the expected average for their school grade, 12 of whom (57.14\%) were below average for a previous grade, only 5 children showed moderate to severe losses $(23.81 \%)$, three children from the third grade and two from the fourth grade, these latter two $(N=5)$ had a performance that from a clinical viewpoint corresponds to DD (Kaufmann et al., 2013). From the AA group $100 \%$ was initially the average expected for their age and 100\% remained in the mean (Santos et al., 2012).

Regarding School Achievement, children from both groups showed better in the re-evaluation of the Writing, Arithmetic and Reading subtest, as well as in the total result, compared to performance in the first evaluation (Table 2).

Detailed analysis of the subtest evaluating school achievement reported lower results from the LA group in relation to the AA group; however, the most representative advances in Post-NMT evaluation were obtained precisely by the LA children, Writing Subtest ( $p s<.001)$, Arithmetic Subtest $(p s<.001)$, Reading Subtest $(p s=.001)$. Accordingly, comparisons of the total row score also showed significant differences, where the LA group showed inferior performance compared to the AA group, the LA children always achieved lower results than their AA peers, but the most representative gains in Post-NMT evaluation were obtained precisely by that group of children ( $p s<.001)$.

Analysis of the composites of Working Memory showed that children with LA obtained higher gains than their peers with AA after NMT for verbal short-term memory, however in the Pre and Post-NMT assessments the LA group obtained lower results than the AA group ( $p s<.001)$. For visuospatial short-term memory, the AA group maintained similar results in the pre- and post-NMT evaluations, but were always better compared to children with LA, despite the fact that they had greater gains in the Post-NMT evaluation ( $p s<.001)$. For verbal working memory there was a group effect, the LA group obtained inferior results to the MR group in the two evaluations, the perceived gains in the post-NMT evaluation were proportionally the same for both groups $(p s<.001)$. For the visuospatial working memory, despite improvements in the scores of the LA children in postNMT evaluation, they still presented lower results than those obtained by their AA peers who maintained equivalent results in the two evaluations $(\not s<.001)$. The mean scores and standard deviation are presented in Table 3.

Table 3. Scores [Average (Standard deviation)] obtained by LA and AA groups in AWMA battery.

\begin{tabular}{|c|c|c|c|c|c|c|c|c|c|c|}
\hline \multirow[t]{2}{*}{ AWMA } & \multicolumn{2}{|c|}{$\mathrm{LA}(N=21)$} & \multicolumn{4}{|c|}{$\mathrm{AA}(N=21)$} & \multirow[b]{2}{*}{ Effects } & \multirow[b]{2}{*}{$F$} & \multirow[b]{2}{*}{$p$} & \multirow[b]{2}{*}{$\eta^{2}$} \\
\hline & Pre-NMT & Post- NMT & RG & Pre- NMT & Post-NMT & RG & & & & \\
\hline$\overline{\text { Digit Recall }}$ & $21.24(3.68)$ & $23.04(2.26)$ & .08 & $26.62(3.77)$ & $27.28(3.30)$ & .03 & & & & \\
\hline Word Recall & $19.67(2.79)$ & $21.71(2.49)$ & .10 & $22.38(2.31)$ & $22.52(2.97)$ & .01 & & & & \\
\hline Nonword recall & $10.95(2.78)$ & $15.66(3.30)$ & .43 & $16.19(4.00)$ & $16.33(3.39)$ & .01 & & & & \\
\hline \multirow[t]{3}{*}{ Verbal short-term memory } & $51.86(7.43)$ & $61.04(5.58)$ & .18 & $65.67(6.48)$ & $66.23(7.04)$ & .01 & Group & 24.40 & $<.01$ & .39 \\
\hline & & & & & & & Time & 21.90 & $<.01$ & .36 \\
\hline & & & & & & & Interaction & 15.80 & $<.01$ & .29 \\
\hline Dot Matrix & $14.00(2.38)$ & $19.28(2.81)$ & .38 & $22.90(3.43)$ & $22.52(2.73)$ & -.01 & & & & \\
\hline Mazes Memory & $13.14(4.43)$ & $18.33(4.50)$ & .39 & $19.95(3.87)$ & $20.90(3.80)$ & .05 & & & & \\
\hline Block Recall & $15.86(3.48)$ & $17.04(3.48)$ & .07 & $20.81(4.10)$ & $21.61(2.72)$ & .04 & & & & \\
\hline Visuospatial short-term & $43.00(6.91)$ & $56.28(5.76)$ & .31 & $63.66(8.19)$ & $65.66(5.82)$ & .03 & Group & 51.30 & $<.01$ & .57 \\
\hline \multirow[t]{2}{*}{ Memory } & & & & & & & Time & 77.10 & $<.01$ & .66 \\
\hline & & & & & & & Interaction & 3.10 & .09 & .07 \\
\hline \multicolumn{11}{|l|}{ Processing } \\
\hline Listening Recall & $8.24(2.34)$ & $10.28(2.66)$ & .25 & $10.33(2.37)$ & $12.28(1.70)$ & .19 & & & & \\
\hline Counting Recall & $6.05(2.51)$ & $15.28(3.77)$ & 1.53 & $11.19(4.07)$ & $15.76(3.30)$ & .41 & & & & \\
\hline Backwards Digit Recall & $8.38(3.15)$ & $9.09(2.16)$ & .08 & $11.00(3.72)$ & $11.85(3.08)$ & .08 & & & & \\
\hline \multirow[t]{3}{*}{ Verbal Working Memory } & $22.66(5.41)$ & $34.66(5.69)$ & .53 & $32.52(8.80)$ & $39.42(5.99)$ & .21 & Group & 2.50 & $<.01$ & .34 \\
\hline & & & & & & & Time & 64.90 & $<.01$ & .63 \\
\hline & & & & & & & Interaction & 5.50 & .03 & .12 \\
\hline Odd-one Out & $10.67(3.23)$ & $15.00(3.49)$ & .41 & $16.62(3.84)$ & $20.28(3.16)$ & .22 & & & & \\
\hline Mister X & $10.71(3.28)$ & $13.48(3.35)$ & .26 & $16.00(5.21)$ & $19.52(3.55)$ & .22 & & & & \\
\hline Spatial Span & $11.19(4.75)$ & $15.04(3.04)$ & .34 & $17.67(3.75)$ & $18.00(3.28)$ & .02 & & & & \\
\hline \multirow[t]{3}{*}{ Vísuospatial working memory } & $35.33(7.05)$ & $40.76(7.11)$ & .15 & $54.28(8.60)$ & $54.80(9.14)$ & .01 & Group & 54.80 & $<.01$ & .58 \\
\hline & & & & & & & Time & 55.60 & $<.01$ & .59 \\
\hline & & & & & & & Interaction & 2.10 & .15 & .05 \\
\hline
\end{tabular}

Note. NMT: numeracy musical training. LA: low arithmetic achievement, AA: average arithmetic achievement, RG: relative gain. AWMA: Automated Working Memory Assessment (AWMA). Each compound is the average score of the three subtests comprising it.

In Behavioral Scales, specifically in the Child Stress Symptom Inventory, children with LA showed more evidence of physical stress reactions compared to their MR peers, alt- hough these differences between groups were not significant, there was a decrease in physical reactions after the NMT for both groups ( $p s=.14$ ); the same for psychological reactions 
( $p s=.60)$; as for psychological reactions with depressive components $(p s=.98)$ and psychophysiological stress reactions $(p s=.48)$, there were significant differences between groups, the LA children showing more pronounced stress reactions than AAs, which was reduced in the post-NMT evaluation. However, some children showed signs of stress distributed as follows: 5 children from the AA group and 11 from the LA group, representing $23.81 \%$ and $52.38 \%$, respectively.

Regarding the Anxiety Scale for Children, a decrease in math anxiety was observed in both groups of children in
post-NMT assessment, the LA children were slightly more anxious than the AA children in the NMT - pre and post assessments $(p s=.02)$.

The results of the Self-Efficacy Scale for Children indicated that those from the LA and AA groups self-evaluated in the same way in the academic, social and emotional areas, improvements were seen in post-NMT evaluation for social self-efficacy $(p s=.58$ ). (Data from the three behavioural scales presented in Table 4).

Table 4. Scores [Average (Standard deviation)] obtained by LA and AA groups in Behavioural Scales.

\begin{tabular}{|c|c|c|c|c|c|c|c|}
\hline \multirow[b]{2}{*}{ Child Stress Symptom Scale } & \multicolumn{2}{|c|}{$\mathrm{LA}(N=21)$} & \multicolumn{3}{|c|}{$\mathrm{AA}(N=21)$} & \multirow[b]{2}{*}{ Effects } & \multirow[b]{2}{*}{$F \quad p \quad \eta^{2}$} \\
\hline & Pre-NMT & Post- NMT & RG & Pre- NMT & Post-NMT & & \\
\hline \multirow[t]{3}{*}{ Physical reactions } & $9.90(6.13)$ & $8.66(4.05)$ & -.13 & $7.57(4.69)$ & $6.80(4.43)$ & -.10 Group & 2.40 .13 .06 \\
\hline & & & & & & Time & 2.30 .14 .05 \\
\hline & & & & & & Interaction & .10 .72 .03 \\
\hline \multirow[t]{3}{*}{ Psychological reactions } & $15.38(6.69)$ & $14.00(6.10)$ & -.09 & $11.38(7.18)$ & $1.80(7.13)$ & -.05 Group & 3.40 .07 .08 \\
\hline & & & & & & Time & .30 .60 .07 \\
\hline & & & & & & Interaction & 1.60 .21 .04 \\
\hline \multirow[t]{3}{*}{ Psychological reactions with depressive components } & $1.04(7.58)$ & $8.57(5.16)$ & -.15 & $6.00(5.44)$ & $4.57(4.85)$ & -.24 Group & 6.80 .01 .14 \\
\hline & & & & & & Time & .00 .98 .01 \\
\hline & & & & & & Interaction & 2.40 .12 .05 \\
\hline \multirow[t]{3}{*}{ Psychophysiological reactions } & $11.04(4.83)$ & $11.61(5.60)$ & .05 & $7.04(4.64)$ & $7.42(5.42)$ & .05 Group & 8.10 .01 .17 \\
\hline & & & & & & Time & .50 .48 .01 \\
\hline & & & & & & Interaction & .00 .89 .01 \\
\hline \multicolumn{8}{|l|}{ Child Stress Symptom Inventory } \\
\hline \multirow[t]{3}{*}{ Academic self-efficacy } & $23.04(4.82)$ & $22.95(5.92)$ & -.004 & $25.33(3.54)$ & $25.04(4.01)$ & -.01 Group & 3.70 .06 .09 \\
\hline & & & & & & Time & .83 .00 \\
\hline & & & & & & Interaction & .00 .92 .00 \\
\hline \multirow[t]{3}{*}{ Social Self-efficacy } & $3.57(6.47)$ & $29.00(6.53)$ & -.05 & $32.90(5.20)$ & $3.09(3.01)$ & -.09 Group & 1.70 .20 .04 \\
\hline & & & & & & Time & 4.30 .04 .10 \\
\hline & & & & & & Interaction & .30 .56 .01 \\
\hline \multirow[t]{3}{*}{ Emotional Self-efficacy } & $27.42(4.47)$ & $26.19(7.85)$ & -.04 & $27.04(6.06)$ & $27.42(4.47)$ & .01 Group & 1.40 .25 .03 \\
\hline & & & & & & Time & .30 .58 .02 \\
\hline & & & & & & Interaction & .80 .37 .02 \\
\hline \multirow[t]{3}{*}{ Math-AS } & 73.42 & 61.71 & -.15 & 65.09 & 61.09 & -.06 Group & .80 .38 .02 \\
\hline & $(17.31)$ & $(15.75)$ & & $(23.58)$ & $(19.91)$ & Time & 5.90 .02 .13 \\
\hline & & & & & & Interaction & 1.40 .24 .04 \\
\hline
\end{tabular}

Note. NMT: numeracy musical training. LA: low arithmetic achievement, AA: average arithmetic achievement, RG: relative gain. Math-AS: Math Anxiety Scale.

\section{Discussion}

NMT (numeracy musical training) was originally employed to stimulate the numerical cognition of preschool children (Silva, Baldin, \& Santos, 2017). In the present study this programme has been tested as an intervention to ameliorate numerical cognition deficits in children with low performance in mathematics. The groups were paired in socioeconomic level, abstract visual reasoning (intellectually upper middle) and age. For this purpose, we carried out a casecontrol, double-blind, and prospective study contrasting school age children with low (LA) and average arithmetic achievement (AA) in cognitive abilities, evaluated in two moments: pre-NMT and post-NMT. Findings suggest that 8 NMT sessions produce near transfer (counting backward, dictation and number reading, mental calculation and prob- lem solving) and partially a far transfer (verbal working memory). However, the findings of far transfers should be met with caution (Melby-Lervåg \& Hulme, 2013; Sala \& Gobet, 2017) considering circumstances of the research discussed further.

Based on Brazilian normative data for numerical cognition (Santos et al., 2012), the LA children found difficulty in performing addition and subtraction tasks in pre-NMT, in understanding numerical symbols and their reproduction; as well as severe deficits in calculation which are substantial for diagnosis of DD (Kaufmann \& von Aster, 2012; Kaufmann et al., 2013; Kucian et al., 2011). Consequently, the present sample is expected to present low response to training since deficits of numerical cognition are usually persistent in children with DD (Mazzocco, \& Räsänen, 2013). It should be noted that the persistence of deficits in the systems of nu- 
merical cognition following intervention is a confirmatory element in the diagnosis of specific learning disabilitity (Kaufmann et al., 2013).

Overall numerical cognition in the first evaluation showed that LA children obtained worse scores compared to AA children for nine Zareki-R subtests. But impairment reduced for seven subtests in the second evaluation. In fact, $28.47 \%$ of children obtained expected results for their age in the second evaluation, according to the normative study (Santos et al., 2012). Their School Achievement score after NMT was congruent to this, some children on LA group still showed results below those expected for the grade. However, children from both groups generally achieved better scores in school performance, even in the arithmetic subtest. Usually business as usual do not produce significant changes in cognitive performance in such small interval of time, suggesting a possible effect of the intervention (Katsh \& MerleFishman, 1985).

As for counting backwards, reading and dictation of numbers, as well as mental calculation tests and problem solving, the performance of the LA group even after intervention, was lower in relation to normative data (Santos et al., 2012). On the other hand, according to interactions, NMT promoted enhancement in children as regards these tasks. Results are consistent with the findings of Spelke (2008) and Ribeiro and Santos (2017) suggesting that NMT helps develop logical-mathematical reasoning (Rauscher et al., 1997) and the manipulation of symbols (Smedt, Noël, Gilmore, \& Ansari, 2013; von Aster \& Shalev, 2007). These findings are promising, since previously advance has been seen after only 8 NMT sessions. Although it must be noted that in the study by Silva, Baldin, and Santos (2017) children performed NMT as a way of stimulating skills, without there being deficits; in the present study children with LA were initially below expectations.

According to medical records, the observed gains do not appear related to the ages of the parents in years, level of schooling and work situation, neither to complications during pregnancy, childbirth (birth weight and prematurity) as there were no differences between groups in this regard. In addition, socioeconomic level seems not to have influenced the results of the neuropsychological evaluations as groups were equivalent (Arias-Rodríguez, Nascimento, \& Santos, 2017; Santos et al., 2012).

Despite the musical intervention offered, some aspects of numerical cognition in children with DD were resistant to treatment (Ribeiro, 2013; Ribeiro \& Santos, 2017), suggesting that perhaps more intervention time is required, e.g. Ribeiro and Santos (2017) obtained improvements in children with DD after 14 sessions of music training. For instance, we did not observe group effect, time or interactions in the counting dots and perceptive estimation tasks, achieving the expected score for age. Although there were differences between groups in the written comparison and contextual estimation tasks, there were no improvements in the post-test of these specific skills.
Regarding far transfers, two cognitive measures of our protocol must be accounted. Pre-and post-NMT comparison showed progress regarding abstract visual reasoning similar to previous studies (Moreno, et al., 2011; Rauscher \& Zupan, 2000; Schellenberg \& Mankarious, 2012), however there was no interaction, consequently no direct relationship with music training can be inferred. As for working memory, the findings of the present study show that the LA group was inferior to the AA group in the two evaluations. Deficits in working memory are actually common in children with numerical cognition dysfunction (Alloway \& Passolunghi, 2011; Geary, 1993), and often observed in children with secondary DD (Kaufmann, et al., 2013). Despite better scores in posttraining, no interactions were seen for the visuospatial shortterm and working memory tasks, because the LA group maintained a worse performance in post-test compared to the AA group (Ribeiro \& Santos, 2012). The benefits of NMT were limited to the verbal component of the working memory, corroborating the meta-analysis of Melby-Lervåg and Hulme (2013), and partially the study by Ribeiro and Santos (2012), where better scores were observed for storing information and processing control following musical stimulation.

As for results of behavioural scales, groups did not differ statistically nor present clinical symptoms of depression, stress, or low self-efficacy in the post-NMT evaluation; except some children from both groups who showed signs of stress (Lipp \& Lucarelli, 1998), perhaps because the school year final exams coincided with the post-NMT evaluations. An important finding was the decrease mathematical anxiety in children from both groups after NMT evaluation suggesting that music has an impact on emotional aspects, bringing about improved self-esteem and self-confidence, providing self-discipline and promoting motivation for learning in general (Gan, Lim, \& Haw, 2015). However, it can be inferred that extending NMT exposure time could provide greater progress for children with DD (Ribeiro, 2013).

\section{Limitations}

Research compared LA and AA groups before and following NMT intervention, evidencing significant improvements in the second assessment for numerical cognition and working memory. However, a third group was not studied with children who had not been subjected to intervention. Consequently, some differences found can hypothetically be explained by age development, influence of school learning or by repetition of cognitive tasks and behavioural scales. In our sample the performance of the children was contrasted with the normative data, which to some extent alike a not trained control group. In research by Silva, Baldin, and Santos (2017) Brazilian preschool children carried out the current NMT, however, there was a control group formed by untrained participants. Only children who participated in NMT showed improvements in learning skills, particularly in mathematics and working memory. Moreover, school activi- 
ties during the interval between assessments for the untrained group did not interfere in progresses, as control group performed equally in both evaluations. Since the time elapsed between assessments was the same in both studies it can be inferred that present findings are probably related to NMT.

A possible explanation for the difference between the evaluations could be the "testing effect" (Roediger \& Butler, 2011), if it was the case, both groups should have obtained an equivalent improvement in all instruments, which did not occur in this study as confirmed by the relative gains in tables 2, 3 and 4. In our research, LA group showed more expressive relative gains across the time as the AA group already had good capacity in the evaluated skills, while the LA group had "more room to grow". Changes were corroborated by a large effect size and this was observed in several items analysed. In addition, children comprising the sample were selected through careful evaluation, and the variables under study were rigorously analysed.

\section{Conclusions}

After the 8 group sessions of NMT we observed a decrease in mathematics anxiety and improvements in counting back-

\section{References}

Alloway, T. P., Gathercole, S. E., Kirkwood, H., and Elliott, J. (2009). The cognitive and behavioral characteristics of children with low working memory. Child Development, 80(2), 606-621. DOI: 10.1111/j.14678624.2009.01282.x

Alloway, T. P. and Passolunghi, M. C. (2011). The relationship between working memory, IQ, and mathematical skills in children. Learning and $\begin{array}{llll}\text { Individual Differences, } & \text { 21(1), }\end{array}$ https://doi.org/10.1016/j.lindif.2010.09.013

Anvari, S. H., Trainor, L. J., Woodside, J., and Levy, B. A. (2002). Relations among musical skills, phonological processing, and early reading ability in preschool children. Journal of Experimental Child Psychology, 83,111-120. DOI: 10.1016/S0022-0965(02)00124-8

American Psychiatric Association. Diagnostic and statistical manual of mental disorders (DSM-5). 5th ed. Arlington: APA; 2013.

Arias-Rodriguez, I., Nascimento, J. M., and Santos, F. H. (2017). Perfil de niños con déficits en la cognición numérica. Universitas Psychologica, 16(3). DOI: https://doi.org/10.11144/Javeriana.upsy16-3.pndc

Baddeley, A. D., and Hitch, G. J. (1974). Working memory. In B. G. (Ed.). The psychology learning and motivation (Vol. 8, pp. 47-90). New York Academic Press.

Bastos, J. A., Cecato, A. M. T., Martins, M. R. I., Grecca, K. R. R., and Pierini, R. (2016). The prevalence of developmental dyscalculia in Brazilian public school system. Arquivos de Neuro-psiquiatria, 74(3), 201-206. DOI: http://dx.doi.org/10.1590/0004-282X20150212

Cohen Kadosh, R., and Walsh, V. (2009). Numerical representation in the parietal lobes: Abstract or not abstract? Behavioral and Brain Sciences, 32, 313 328. DOI: http://dx.doi.org/10.1017/S0140525X09990938

Costa-Giomi, E. (1999). The effects of three years of piano instruction on children's cognitive development. Journal of Research in Music Education, 47, 198-212. DOI: http://dx.doi.org 10.2307/3345779

Da Silva, E. R., Baldin, M.S., and Santos, F. H. (2017). Cognitive effects of numeracy musical training in Brazilian preschool children: A prospective pilot study. Psychology and Neuroscience, 10(3), 281. DOI: http://dx.doi.org/10.1037/pne0000098 wards, reading and dictation of numbers, arithmetic as well as word problem solving, and to a lesser extent in verbal working memory. Despite evolving in relation to deficits presented in the first evaluation, children still showed problems in some areas such as calculation, and in working memory tasks (non-numerical cognitive dysfunctions). Certain difficulties (e.g. oral and written comparisons, contextual estimation) were resistant to treatment, at least with a short duration. This profile suggests the diagnosis of secondary DD. In conclusion, NMT provided beneficial effects in the performance of numerical cognition tasks for children with DD.

Acknowledgements.- We especially thank the parents and children for their participation and acknowledge the cooperation of the government schools at Bauru city in São Paulo State. This project was supported by the CNPQ (National Council for Scientific and Technological Development), Brazil, PEC-PG case $\mathrm{n}^{\circ}$ 190249/2012-9. We also thank Professor Agustín Romero Medina from University of Murcia for helpful comments and Barry Noonan for reviewing the manuscript.

Devine, A., Soltész, F., Nobes, A., Goswami, U., and Szűcs, D. (2013). Gender differences in developmental dyscalculia depend on diagnostic criteria. Learning and Instruction, 27, 31-39. DOI: http://dx.doi.org/10.1016/j.learninstruc.2013.02.004

Esteki, M. (2013). Effectiveness of "Music Training" on reorganization of brain and poor intellectual abilities in female students with dyscalculia (7-9 years old). Global Journal of Arts Education, 3, 06-10. DOI: http://www.world-educationcenter.org/index.php/gjae/article/viewArticle/2836

Eugênio, M.; Escalda, J. and Lemos, S. (2012). Desenvolvimento cognitivo, auditivo e linguístico em crianças expostas à música: produção de conhecimento nacional e internacional. Revista CEFAC, 2012, vol. 14, no 5, p. 992-1003.

Gan, S. K. E., Lim, K. M. J., and Haw, Y. X. (2016). The relaxation effects of stimulative and sedative music on mathematics anxiety: A perception to physiology model. Psychology of Music, 44(4), 730-741. DOI: $10.1177 / 0305735615590430$

Geary, D. C. (1993). Mathematical disabilities: Cognitive, neuropsychological, and genetic components. Psychological Bulletin, 114(2), 345. DOI: http://psycnet.apa.org/doi/10.1037/0033-2909.114.2.345

Herrera, A., and Maldonado, A. (2002). Depresión, cognición y fracaso académico. International Journal of Clinical and Health Psychology, 2(1). DOI: http://www.redalyc.org/html/337/33720102/

Ho, Y. C. Cheung, M. C. and Chan, A. S. (2003). Music training improves verbal but not visual memory: cross-sectional and longitudinal explorations in children. Neuropsychology, 17(3), 439-450. DOI: http://dx.doi.org/10.1037/0894-4105.17.3.439

Iuculano, T., Rosenberg-Lee, M., Richardson, J., Tenison, C., Fuchs, L. Supekar, K., and Menon, V. (2015). Cognitive tutoring induces widespread neuroplasticity and remediates brain function in children with mathematical learning disabilities. Nature Communications, 6, 8453. DOI: 10.1038/ncomms9453

Katsh, S., and Merle-Fishman, C. (1985). The music within you. Barcelona Publishers. 
Kaufmann, L., Mazzocco, M. M., Dowker, A., von Aster, M., Göbel, S. M., Grabner, R. H., and Nuerk, H. C. (2013). Dyscalculia from a developmental and differential perspective. Frontiers in Psychology, 4. DOI: 10.3389 /fpsyg.2013.00516

Kaufmann, L., and von Aster, M. (2012). The diagnosis and management of dyscalculia. Deutsches Ärțeblatt International, 109(45), 767. DOI: 10.3238/arztebl.2012.0767

Koelsch, S., and Siebel, W. A. (2005). Towards a neural basis of music perception. Trends in Cognitive Sciences, 9(12), 578-584. DOI: http://dx.doi.org/10.1016/j.tics.2005.10.001

Krinzinger, H., Kaufmann, L., and Willmes, K. (2009). Math anxiety and math ability in early primary school years. Journal of Psychoeducational Assessment, 27(3), 206-225. DOI: 10.1177/0734282908330583

Kucian, K., Grond, U., Rotzer, S., Henzi, B., Schönmann, C., Plangger, F., ... and von Aster, M. (2011). Mental number line training in children with developmental dyscalculia. NeuroImage, 57(3), 782-795. DOI: https://doi.org/10.1016/j.neuroimage.2011.01.070

Lamminmaki, T., Ahonen, T.,and Todd de Barra, H. (1997) . Two-year group treatment for children with learning difficulties: Assessing effects of treatment duration and pretreatment characteristics. Journal of Learning Disabilities, 30, 354-364. DOI: 10.1177/002221949703000401

Lipp, E. M.N. and Lucarelli, M.D.M (1998). Escala de Stress Infantil (ESI). São Paulo: Casa do Psicólogo.

Machin, D., and Fayers, P. M. (2010). Randomized clinical trials: Design, practice and reporting. Hoboken, NJ: Wiley. DOI: http://dx.doi.org/10.1002/ 9780470686232

Mazzocco, M. M. M. (2007). Defining and differentiating mathematical learning disabilities and difficulties. In D. B. Berch and M. M. M. Mazzocco (Eds.), Why is math so hard for some children? The nature and origins of mathematical learning difficulties and disabilities (pp. 29-47). Baltimore: Paul $\mathrm{H}$ Brookes Publishing.

Mazzocco, M. M., and Räsänen, P. (2013). Contributions of longitudinal studies to evolving definitions and knowledge of developmental dyscalculia. Trends in neuroscience and education, 2(2), 65-73. DOI: https://doi.org/10.1016/j.tine.2013.05.001

Melby-Lervåg, M., and Hulme, C. (2013). Is working memory training effective? A meta-analytic review. Developmental psychology, 49(2), 270. DOI: $10.1037 / \mathrm{a} 0028228$

Melo, R. M. D., Hanna, E. S., and Carmo, J. D. S. (2014). Ensino sem erro e aprendizagem de discriminação. Temas em Psicologia, 22(1), 207-222. DOI: 10.9788/TP2014.1-16

Menezes, Ebenezer Takuno de; Santos, Thais Helena dos. Verbete progressão continuada. Dicionário Interativo da Educação Brasileira - Educabrasil. São Paulo: Midiamix, 2001. Disponível em: http://www.educabrasil.com.br/progressao-continuada/. Acesso em: 14/12/2017.

Michels, L., O'Gorman,R., and Kucian, K.(2017). Functional hyperconnectivity vanishes in children with developmental dyscalculia after numerical intervention. Developmental Cognitive Neuroscience, 30, 291-303. DOI: 10.1016/j.den.2017.03.005

Moreno, S., Bialystok, E., Barac, R., Schellenberg, E. G., Cepeda, N. J., and Chau, T. (2011). Short-term music training enhances verbal intelligence and executive function. Psychological Science, 22(11), 1425-1433. DOI: $10.1177 / 0956797611416999$

Pina, V., Fuentes, L. J., Castillo, A., and Diamantopoulou, S. (2014). Disentangling the effects of working memory, language, parental education, and non-verbal intelligence on children's mathematical abilities. Frontiers in Psychology, 5, 415. DOI: 10.3389/fpsyg.2014.00415

Ramírez, G., Chang, H., Maloney, E. A., Levine, S. C., and Beilock, S. L. (2016). On the relationship between math anxiety and math achievement in early elementary school: the role of problem solving strategies. Journal of Experimental Child Psychology, 141, 83-100. DOI: https://doi.org/10.1016/j.jecp.2015.07.014

Räsänen, P., Salminen, J., Wilson, A. J., Aunio, P., and Dehaene, S. (2009). Computer-assisted intervention for children with low numeracy skills. Cognitive Development, 24(4), 450-472. DOI: 10.1016/j.cogdev.2009.09.003

Rauscher, F. H., Shaw, G. L., Levine, L. J., Wright, E. L., Dennis, W. R., and Newcomb, R. L.(1997). Music training causes long-term enhance- ment of preschool children's spatial-temporal reasoning. Neurological Research, 19(1),

$2-8$.

https://doi.org/10.1080/01616412.1997.11740765

Rauscher, F., H., and Zupan, M. A. (2000). Classroom Keyboard Instruction Improves Kindergarten Children's Spatial-Temporal Performance: A Field Experiment. Early Childhood Research Quarterly, 15, 215-228. DOI: 10.1016/S0885-2006(00)00050-8

Ribeiro, F. S. and Santos, F. H. (2015). Métodos específicos para impulsionar a memória. In: Santos, F. H., Andrade, V. M. and Bueno, O. F. A. (Eds), Neuropsicologia hoje (2nd ed). Porto Alegre, RS: Artmed.

Ribeiro, F. S., and Santos, F.H. (2012). Treino musical e capacidade da memória operacional em crianças iniciantes, veteranas e sem conhecimentos musicais. Psicologia Reflexão e Crítica, 25, 559-567. DOI: http://www.scielo.br/revistas/prc/iaboutj.htm

Ribeiro, F. S., and Santos, F. H. (2017). Enhancement of numeric cognition in children with low achievement in mathematic after a noninstrumental musical training. Research in Developmental Disabilities, 62, 26-39. DOI: https://doi.org/10.1016/j.ridd.2016.11.008

Roediger, H. L., and Butler, A. C. (2011). The critical role of retrieval practice in long-term retention. Trends in cognitive sciences, 15(1), 20-27. DOI: https://doi.org/10.1016/j.tics.2010.09.003

Rubinsten, O., and Tannock, R. (2010). Mathematics anxiety in children with developmental dyscalculia. Behavioral and Brain Functions, 6(1), 46. DOI: 10.1186/1744-9081-6-46.

Sala, G., and Gobet, F. (2017). Does far transfer exist? Negative evidence from chess, music, and working memory training. Current directions in psychological science, 26(6), 515-520. DOI: $10.1177 / 0963721417712760$

Santos, F. H. and Engel, P. M. J. (2008). Adaptação Brasileira da AWMA: "Automated Working Memory Assessment”. In: Ortiz, L., Mendonça, A., Foz, C. B.; Santos, D., Fuentes, D. A. Azambuja (Orgs.). Avaliação neuropsicológica: Panorama interdisciplinar dos estudos atuais na normatização e validação de instrumentos no Brasil. São Paulo, SP: Vetor.

Santos, F. H., Silva, P. A., Ribeiro, F. S., Dias, A. L. R. P., Frigério, M. C., Dellatolas, G., and von Aster, M. (2012). Number processing and calculation in Brazilian children aged 7-12 years. The Spanish Journal of Psychology, 15(02), 513-525. https://doi.org/10.5209/rev_SJOP.2012.v15.n2.38862

Schellenberg, E. G., and Mankarious, M. (2012). Music training and emotion comprehension in childhood. Emotion, 12(5), 887. DOI: $10.1037 /$ a0027971

Schiavio, A., van der Schyff, D. 4E Music Pedagogy and the Principles of Self-Organization Behav. Sci. 2018, 8, 72; doi:10.3390/bs8080072

Silva, P. A., Ribeiro, F. S., and Santos, F. H. (2015). Cognição numérica em crianças com transtornos específicos de aprendizagem. Temas em Psicologia, 23(1), 197-210. DOI: 10.9788/TP2015.1-13

Silva, P. A., and Santos, F.H. (2012). Discalculia do Desenvolvimento: Avaliação da representação numérica pela ZAREKI-R. Psicologia: Teoria e Pesquisa, 27, 169-177. DOI: http://dx.doi.org/10.1590/S010237722011000200003

Smedt, B., Noël, M. P., Gilmore, C., and Ansari, D. (2013). How do symbolic and non-symbolic numerical magnitude processing skills relate to individual differences in children's mathematical skills? A review of evidence from brain and behavior. Trends in Neuroscience and Education, 2(2), 48-55. DOI: https://doi.org/10.1016/j.tine.2013.06.001

Snyder, M.C., and Bambara, L.M. (1997). Teaching secondary students with learning disabilities to self-manage classroom survival skills. Journal of learning disabilities, 30, 534-543. DOI: 10.1177/002221949703000509

Spelke, E. (2008). Effects of music instruction on developing cognitive systems at the foundations of mathematics and science. Learning, Arts, and the Brain, vol. $17 . \quad$ DOI: http://www.webmail.dana.org/uploadedFiles/News_and_Publications /Special_Publications/Learning, $\% 20$ Arts $\% 20$ and $\% 20$ the $\% 20$ Brain_Ar tsAndCognition_Compl.pdf\#page $=27$

Stein, L. M. (1994). TDE: Teste de Desempenho Escolar: manual para aplicação e interpretação. São Paulo: Casa do Psicólogo.

Von Aster, M., and Shalev, R. S. (2007). Number development and developmental dyscalculia. Developmental Medicine and Child Neurology, 49, 868873. DOI: $10.1111 /$ j.1469-8749.2007.00868.x 
Williamson, V. J., Baddeley, A. D., and Hitch, G. J. (2006). Music in working memory? Examining the effect of pitch proximity on the recall performance of non musicians. In $9^{\text {th }}$ International Conference on Music Perception and Cognition (pp. 1581-1590). DOI:http:// citeseerx.ist.psu.edu/viewdoc/download?doi=10.1.1.603.5 $063 \mathrm{yrep}=$ rep 1 type $=$ pdf
Wilson, A. J., Revkin, S. K., Cohen, D., Cohen, L., and Dehaene, S. (2006). An open trial assessment of" The Number Race", an adaptive computer game for remediation of dyscalculia. Behavioral and Brain Functions, 2(1), 20. DOI: https://doi.org/10.1186/1744-9081-2-20

World Health Organization (2018). The ICD-11 Classification of Mental and Behavioural Disorders: Diagnostic Criteria for Research. Geneva. 